\begin{tabular}{|c|c|c|}
\cline { 2 - 3 } & REVISTA SABERES APUDEP & Volumen 3 Número 2 \\
\hline \\
\hline
\end{tabular}

\title{
DIAGNÓSTICO SITUACIONAL DEL SOPORTE TECNOLÓGICO DE LAS CLASES NO PRESENCIALES EN EL CENTRO REGIONAL UNIVERSITARIO DE SAN MIGUELITO
}

\author{
SITUATIONAL DIAGNOSIS OF TECHNOLOGICAL SUPPORT OF NON- \\ PRESENTIAL CLASSES IN THE SAN MIGUELITO REGIONAL UNIVERSITY \\ CENTER \\ Dennis Quintero Cedeño \\ Universidad de Panamá, Centro Regional Universitario de San Miguelito \\ dennis.quintero@up.ac.pa \\ Lorenzo Olivero Z, \\ Universidad de Panamá, Centro Regional Universitario de San Miguelito \\ lorenzoolivero@hotmail.com \\ Jackeline Juárez \\ Universidad de Panamá, Centro Regional Universitario de San Miguelito. \\ jackeline. juárez@up.ac.pa
}

\section{NOTA DE INVESTIGACIÓN \\ RESUMEN}

Este documento expone los resultados preliminares de un estudio en proceso que se desarrolla en el Centro Regional Universitario de San Miguelito, Universidad de Panamá. Con la finalidad de determinar si los estudiantes tienen accesibilidad, tecnológica, para dar las clases no presenciales, Primer Semestre y Segundo Cuatrimestre, atendiendo al Acuerdo de Consejo Académico 3-20 del 11 de marzo de 2020.

PALABRAS CLAVE Clases No presenciales, Accesibilidad académica, Universidad de Panamá

\section{ABSTRCT}

This document presents the preliminary results of a study in progress that is being carried out at the Regional University Center of San Miguelito, University of Panama. In order to determine if the students have accessibility, technological, to give the non-contact classes, First Semester and Second Semester, attending to the Agreement of the Academic Council 3-20 of March 11, 2020.

KEY WORDS Non-contact classes, Academic accessibility, Panama University 


\begin{tabular}{|c|c|c|}
\cline { 2 - 3 } & REVISTA SABERES APUDEP & Volumen 3 Número 2 \\
\hline
\end{tabular}

El 30 de enero de 2020 la Organización Mundial de la Salud (OMS) declara Covid19, como situación de emergencia de salud pública de importancia internacional. Posteriormente, el 12 de marzo de 2020 la OMS declara el brote como una pandemia. OMS (2020).

A raíz de la situación a nivel mundial y la aparición de casos de COVID-19 en Panamá, el Gobierno de la República de Panamá declara el estado de emergencia y cuarentena a nivel nacional, estableciendo entre sus medidas la restricción del movimiento de personas y se suspensión temporal de las clases en los escuelas y universidades de todo el país urgida por el principio de salvaguarda de la salud pública en un contexto en el que las grandes acumulaciones de personas generan, por la naturaleza de la pandemia, graves riesgo (UNESCO, IESAC, 2020)

De forma súbita las universidades oficiales y particulares a nivel nacional debieron enfrentar un gran desafío: "La Educación No Presencial". El Consejo Académico de la Universidad de Panamá, en el acuerdo en reunión $\mathrm{N}^{\circ}$. 3-20, celebrada el 11 de marzo de 2020, aprobó habilitar la modalidad virtual para todos los cursos impartidos el primer semestre académico y segundo ciclo cuatrimestral de 2020.

Recomendando las siguientes opciones de plataformas virtuales: La Dirección de Tecnología de la Información y Comunicación: plataformas Virtual Moodle y Office 365. La Dirección de Tecnología Educativa: plataformas: Edmodo, Schoology, Google Scholar y la Plataforma Moodle, mientras que la Dirección de Entornos Virtuales, la plataforma Campus Virtual-Educativa. La Secretaria General de la Universidad de Panamá, indicaba que los docentes podrán darles seguimiento a sus cursos mediante correo electrónico, grupos de WhatsApp, y módulos de auto instrucción.

Posteriormente el Consejo Académico en acuerdo de reunión $N^{\circ} .5-20$, celebrada el 27 de mayo de 2020, ratifica que el primer y segundo semestre y el segundo y tercer 


\begin{tabular}{|c|c|c|}
\cline { 2 - 3 } & REVISTA SABERES APUDEP & Volumen 3 Número 2 \\
\hline
\end{tabular}

ciclo cuatrimestral del año académico 2020, en la Universidad de Panamá continuará y finalizará en la modalidad no presencial.

La educación a distancia la entendemos como un diálogo didáctico mediado entre el profesor (institución) y el estudiante que, ubicado en espacio diferente al de aquél, aprende de forma independiente y también colaborativa (García Aretio, 2001). En la que se Destacan cuatro componentes esenciales: docencia (institución), aprendizaje (alumnos), materiales (contenidos) y comunicación (vías y canales) que implica el establecimiento de reglas, normas y dinámicas compartidas (Rizo García, 2006).

El 8 de julio de 2020 el Consejo Académico de la Universidad de Panamá en acuerdo de reunión № 6-20 aprobó crear una comisión para reglamentar los procedimientos de las clases virtuales.

De forma paralela, la Universidad de Panamá realizó alianzas estratégicas con los proveedores de internet nacional, con proveedores de software de uso colaborativo como Microsoft Teams y las empresas telefónicas: Cable \& Wireless, Digicel Panamá y Movistar, para incluir el servicio de acceso gratuito en la red de datos móviles, concedido a los estudiantes que ingresen a los servicios de la web de la Universidad de Panamá (dominio up.ac.pa) y sean clientes de estas empresas, para que no consuman su plan de data en sus clases virtuales del primer semestre. Todo esto con el objetivo de brindar herramientas de uso virtual de manera más accesible a los 4155 docentes y a 75,103 estudiantes debidamente matriculados para el primer semestre de 2020 según cifras del portal web de la Universidad de Panamá.

La administración de la Universidad de Panamá tomó medidas inmediatas para el beneficio de los estudiantes, pero, se desconoce el soporte tecnológico que utilizan los docentes y los estudiantes durante las clases No Presenciales del primer y segundo semestre de 2020 . 


\begin{tabular}{|c|c|c|}
\cline { 2 - 3 } & REVISTA SABERES APUDEP & Volumen 3 Número 2 \\
\hline
\end{tabular}

La Administración del Centro Regional Universitario de San Miguelito, Universidad de Panamá, CRUSAM ubicado en una zona vulnerable socialmente por la falta de empleos formales y que atiende una población de 3, 200 estudiantes, preocupada por la calidad del proceso educativo bajo la modalidad no presencial, se pregunta ¿con qué herramientas, plataformas y conectividad cuentan los estudiantes para recibir clases no presenciales y cumplir con las demandas de formación profesional?

En etapa inicial se desarrolla una investigación de enfoque cuantitativo, descriptivo transversal, en la que en su primera fase diagnóstica se aplicó en el mes de mayo una encuesta a estudiantes de todas las facultades del Centro Regional Universitario.

La encuesta fue contestada por 602 estudiantes que representan el $18.9 \%$ de la población estudiantil del CRUSAM. Distribuidos de la siguiente manera: segundo año 218 (36.2\%), tercer año 174 (28.9\%), cuarto año 129 (21.4\%), primer año 43 (7.1\%), un grupo reducido $29(4.8 \%)$ de quinto año; y nueve estudiantes $(1.4 \%)$ graduandos que cursan seminario, tesis o práctica profesional como opción trabajo de grado.

El hallazgo más importante fue que el teléfono celular era el principal dispositivo electrónico con el que contaban (48.7\%); un (25.4\%) usan tableta, computadora y celular; y un (23.4\%) contaban con computadora de escritorio o laptop. Un mínimo porcentaje $(1.6 \%)$ no poseen herramienta para recibir sus clases No presenciales.

Se puede observar que los estudiantes del CRUSAM de primer a tercer año tienen predominantemente como dispositivo electrónico el teléfono celular, limitando el uso del computador fijo o portátil. Esto podría deberse entre otros factores: a la situación económica de gran parte afecta a los estudiantes que recién ingresan al CRUSAM y que una vez consiguen empleo, pueden invertir en una computadora personal. 


\begin{tabular}{|c|c|c|}
\cline { 2 - 3 } & REVISTA SABERES APUDEP & Volumen 3 Número 2 \\
\hline & ISSN L 2644-3805 & Julio-diciembre 2020 \\
\hline
\end{tabular}

El (55.8\%) de los estudiantes encuestados tienen servicio de internet fijo en casa, otro (36.9\%) consumen tarjetas de prepago, para tener internet y recibir sus clases. Un (7.3\%) de estudiantes no contaban con ningún servicio de internet, confrontando la limitación de no poder recibir sus clases.

Con respecto a plataformas educativas, el (33.2 \%) de los estudiantes encuestados no conocían, ni estaban relacionado con ninguna plataforma de educación virtual. El $72 \%$ que manifestó tener algún grado de conocimiento con la utilidad de plataformas señalaron que la Plataforma Microsoft Teams es desconocida para ellos.

A partir de estos datos generados en esta encuesta es importante empezar a trazar las líneas fundamentales para dar accesibilidad a la población estudiantil universitaria CRUSAM.

\section{REFERENCIAS BIBLIOGRÁFICAS}

García Aretio, L. (2001). Perspectivas teóricas de la educación a distancia y virtual. Revista española de pedagogía, № 249, pp. 255-271.

Rizo García, M. (2006). La interacción y la comunicación desde los enfoques de la psicología social y la sociología fenomenológica. Breve exploración teórica. Análisi. 33, 45-62

Sitio Web Organización Mundial para la Salud. (2020). COVID-19: cronología de la actuación de la OMS, 27 de abril. https://www.who.int/es/news-room/detail/27-04-2020-whotimeline---covid-19

UNESCO_IESAIC. (2020). COVID-19 y Educación Superior: de los efectos inmediatosal día despues. Analisis del Impacto, respuestas políticas y recomendaciones.http://www.iesalc.unesco.org/wp-content/uploads/2020/05/COVID-19ES-130520.pdf

Universidad de Panamá. (2009). Modelo Educativo y Académico. Dirección General de Planificación y Evaluación Universitaria.

Universidad de Panamá. (2020). Acuerdo de Consejo Académico №3-20 del 11 de marzo de 2020. Secretaria General. Sección Parlamentaria.

Universidad de Panamá. (2020). Acuerdo de Consejo Académico N5-20 del 27 de mayo de 2020. Secretaria General. Sección Parlamentaria 